\title{
A computer lab for undergraduate psychological research
}

\author{
JOHN S. MONAHAN \\ Central Michigan University, Mt. Pleasant, Michigan
}

\begin{abstract}
This paper describes how funds from an NSF Instrumentation and Laboratory Improvement grant allowed development of a computer lab with a local area network (LAN) for undergraduate research in psychology. The lab has been used mainly in conjunction with an applications of research methods course, but expanded use is expected because of the connection of the LAN to a mainframe computer's LAN, the proposed installation of PSYCLIT on the LAN, and the proposed connection of the LAN to faculty offices. The main experimental software packages used are MEL Lab and Micro Experimental Laboratory (MEL); both are critical to the lab's operation. Funds for maintenance of the lab will be obtained by charging applications course students a lab fee.
\end{abstract}

In November 1989, Hajime Otani, Robert Sinclair, Lynda King, Gary Dunbar, and I applied for a computer laboratory for undergraduate research through an NSF Instrumentation and Laboratory Improvement (ILI) grant and were funded beginning in the Fall of 1990 . The purpose of the grant was to improve a revamped methods course sequence by adding some research experience to the research design course and adding greater variety of experience to the research methods applications course.

Our department had recently changed its research methods requirement for majors from a single methods course to a two-course sequence: research design, including nonexperimental as well as experimental methods, and applications of research methods with some sections devoted to experimental topics and others devoted to nonexperimental topics. One aim was to produce students with some competence in research earlier in their undergraduate careers, thereby increasing the number of directed-research students; this goal has already been achieved. Another aim was to increase the number of students completing a senior thesis; however, this has not yet been achieved. The research design course is taught as a large lecture course (60 students per section, two sections per semester), without a research experience component. The applications course is taught as a small section course (20 students per section, five sections per semester) with empirical research, data analysis, and report writing.

\footnotetext{
This work was supported in part by NSF Grant USE-9051323 and by grants from Central Michigan University. I thank my co-investigatorsHajime Otani, Robert Sinclair, Lynda King, and Gary Dunbar-for their help in preparing the grant application and in setting policies for the implementation of the grant. I also thank the computer lab graduate assistants, Howard Whiteman (now at Purdue), Mark Stimson, and Paul St. Louis, as well as Hajime Otani, for their work in developing the lab. Correspondence may be sent to John Monahan, Department of Psychology, Central Michigan University, Mt. Pleasant, MI 48859.
}

Our original plan called for 12 workstations and a server connected as a Novell local area network (LAN); however, computer prices dropped and we were able to purchase more equipment than we had anticipated. The initial configuration was 12 workstations, a server, 4 stations at which faculty and graduate assistants (GAs) develop software and perform lab administrative tasks, and one station, not connected to the LAN, in another building to serve the needs of those few students in behavioral neuroscience and behavior analysis sections of the applications course. This initial configuration allowed sharing of software modules and some control over lab usage but no access to the mainframe except through a modem attached to one station. We had expected to use SPSSPC software through a university site license, but when the university dropped its license, we were without statistical software in the lab. Affordable choices for PCs were relatively weak, although inexpensive, packages that would not perform repeated measures analyses, reliability analysis, or both. Most sections of the applications course needed either one or both of these analyses. We felt that despite the user unfriendliness of mainframes and of mainframe statistical packages, we would best ensure the long-term stability by teaching the students to use the mainframe statistics packages, as we had done before we acquired a computer lab. Thus, a mainframe connection to the LAN was important to us, and we have subsequently added a high-speed modem connection to the mainframe LAN, giving all of the workstations access to the mainframe.

\section{Using MEL Lab}

The greatest educational change brought about by the ILI grant has been the use of Psychology Software Tools' MEL Lab software (St. James \& Schneider, 1991) as the basis for research in some sections of the applications course. In two or three sections each semester, students conduct 4-7 experiments from MEL Lab. They schedule 
a computer, test themselves individually, then bring their data to a GA for merging into a collective data file. Students subsequently retrieve the file and analyze the data by using a mainframe statistical package, either SAS or SPSS. They then write a partial or complete research report based on the class data. Because of MEL Lab, students are exposed to more experiments (about twice as many) and are better able to discuss alternative experimental procedures for testing the same and similar hypotheses.

The syllabus for the applications course calls for a final research project, with a paper that stays on file with the department, and for an oral presentation of the project to a group of students. Data are collected for a typical final project by an individual student or a pair of students working together. A requirement common to many sections is that the study involve at least two factors, with, if possible, one factor repeated to reduce the need for large numbers of subjects. The experience has been that students who used MEL Lab in their applications sections often choose final projects that involve conducting followup studies of experiments that were conducted in class. Initially, we had little luck in modifying experiments with MEL Lab's experiment editor because we were not able to change the aspects of the experiments that we wanted to change. The newer MEL Lab experiment editor is a major improvement and allows easy changes of parameters such as timing, number of stimuli, and particular stimuli used. Initially, however, we tried three approaches to producing individualized experiments. The simplest approach was to persuade the student that a different MEL Lab experiment, one not used in class, was a good substitute for the desired experiment. This approach worked well for those experiments in MEL Lab that can be seen as following upon each other, such as "scanning shortterm memory" and "additive factors model." Another simple approach was to superimpose an external variable on a MEL Lab experiment. An example of the superimposition approach is to test subjects in "lexical decisions" after a positive or negative mood induction. These two simple approaches take care of most of the students in the course.

The third approach to solving the individual experiment problem has been to have the GAs write programs for students using Micro Experimental Laboratory (MEL; Schneider, 1988). This approach requires GAs who can write MEL programs. The initial senior GA had garnered considerable practice at MEL writing programs for himself and others. In the first semester in which we used this approach, he was able to write eight programs-five were variations on MEL Lab experiments and three were experiments from the literature. He and subsequent GAs have now duplicated in MEL many of the experiments in MEL Lab. We can now modify experiments in a variety of ways to fit individual needs. We will also make considerable use of the newer MEL Lab experiment editor to produce individual programs and will attempt to have applications course students write their own modifications. In using a modified or unmodified experiment from MEL Lab as a final project experiment, we use the MEL Lab files to create a MEL experiment. This step allows students to collect data from a large number of subjects without clearing the data file between subjects.

We are currently attempting to maintain a reasonable level of proficiency in MEL in the lab by selecting GAs with computer skills and training them in MEL. One problem in that regard is that we offer only an MA in experimental psychology, thus the students usually stay only 2 years. To produce a continuing level of proficiency, we must ensure that expertise is passed from one GA class to the next. Therefore, we assign a new graduate student as a GA each year and expect to keep that person for 2 years, thereby avoiding a year with only inexperienced GAs.

Initial learning of MEL usually is accomplished by students studying the users manual and replicating some of the programs. Beyond that, students consult with each other to discover how some routines are to be written. Some undergraduate students also learn MEL, particularly directed-research students. At the end of each school year, we lose a considerable portion of the collective experience in MEL.

\section{Expanding Lab Usage}

Initially, only students in experimental psychology sections of the applications course used the computer lab. In addition to experimental sections, we usually have two developmental sections, a community psychology section, and an additional section, possibly cognitive social learning or social psychology. Instructors who teach these nonexperimental sections do not use MEL Lab. We also have partial sections (three or four students) for behavioral neuroscience and behavior analysis; the labs for these partial sections are located in a different building. Thus, not all applications students have used the computer lab, and this lack of universal use has caused less than complete departmental support for the lab. The obvious solution to these problems has been to initiate computer lab use for the students who are not using MEL Lab.

Nonexperimental applications students, as with experimental students, conduct data analysis using the mainframe computer. Previously these students were taught computer skills by their course instructor in general university labs. Beginning with next semester, we are bringing each of these sections into the computer lab, where the GAs will demonstrate mainframe use and be available for questions and consultation. Three or four sessions are usually needed for students to acquire the necessary basic skills: sign on and off, e-mail, file creation and maintenance, and statistical package basics.

There is a desire by some to push this basic computer instruction back into the research design course. An attempt to do so will be made in the spring semester with a single section of 120 research design students. In this same course, students will participate as subjects and experimenters in one or two experiments written in MEL. The students will analyze their class data using SAS on the mainframe. In the future, an additional computer ex- 
perience for research design students may be exploration of simulated studies using DATASIM (Bradley, 1988).

We are planning a further expansion of computer lab usage by installing PSYCLIT on the LAN, depending on anticipated funding. All applications students use PSYCLIT and their use of it on the LAN will create additional support for the lab. We plan to extend the LAN to faculty offices in the Summer and Fall of 1993, depending on funding.

Finally, the cognitive social learning instructor has found some software that fits the social-problem-solving research that his applications students perform. He plans to test the software this summer and use it in his applications class in the fall. We are encouraging other nonexperimental instructors to follow suit.

\section{Maintaining a Viable Lab}

We are concerned with ensuring funding to maintain the lab for the future. Currently, the workstations are PC clones, 386SX-20 MHz, with Super VGA displays and $2 \mathrm{MB}$ of memory. These are adequate for the present, especially considering the lack of psychological software that takes full advantage of the 386/486 hardware. Replacement of aging monitors is estimated to cost about $\$ 3,000$ over 5 years. An estimate of the cost of an upgraded video standard would be about $\$ 700$ per computer, that is, $\$ 8,400$ for 12 workstations. There are many other workstation and server maintenance problems that may arise that may cost as much as $\$ 3,600$ over 5 years. Finally, we may need to upgrade the processors and memory on the workstations or server, or upgrade the hard disk on the server. Processor and memory upgrades would cost about $\$ 700$ per workstation and about $\$ 1,500$ for the server. Hard disk upgrade for the server might cost $\$ 1,500$. The total cost of maintenance and upgrades could exceed $\$ 26,000$, much more than the department could ever consider funding from its normal budget.
We need to be able to obtain funds over a few years in order to perform maintenance and upgrading as needed. The most important current possibility is a lab fee for applications course students. We have about 200 applications course students per year, thus a $\$ 20$ lab fee would generate about $\$ 4,000$ per year, or $\$ 20,000$ over 5 years. The expansion of lab use, especially the anticipated installation of PSYCLIT, has solidified departmental support for a lab fee.

Two years ago, another college within the university proposed a computer lab fee. The fee was approved by the council of deans but disapproved by the central administration. Two arguments were given. First, administrators argued that new lab fees were not appropriate because students had already paid for the course with tuition. Only lab fees for breakage or abnormal wear and tear could be supported. They also argued that lab fees would go into the University's General Fund. However, more difficult economic times, changes in the board of trustees, and a new president have led to the current circumstances in which computer lab fees for some courses have been approved, with proceeds going to the department charging the fee. Those computer lab fees are expected to be implemented in the Fall of 1993. Because the department chairperson and the dean favor a computer lab fee and because the current president favors computer lab fees in general, we expect to implement a computer lab fee in the near future to help pay for lab maintenance.

\section{REFERENCES}

Bradley, D. R. (1988). DaTASIM. Lewiston, ME: Desktop Press. SCHNEIDER, W. (1988). Micro Experimental Laboratory: An integrated system for IBM PC compatibles. Behavior Research Methods, Instruments, \& Computers, 20, 206-217.

St. JAMES, J., \& SCHNEIDER, W. (1991). MEL lab: Experiments in perception, cognition, social psychology, and human factors (Version 1.5). Pittsburgh: Psychology Software Tools. 